\title{
Food and alcohol disturbance among young adults during the COVID-19 lockdown in Italy: risk and protective factors
}

\author{
Sara Pompili ${ }^{1}$ - Daniele Di Tata ${ }^{1}$ - Dora Bianchi ${ }^{1} \cdot$ Antonia Lonigro $^{2} \cdot$ Marta Zammuto $^{1} \cdot$ Roberto Baiocco $^{1}$. \\ Emiddia Longobardi ${ }^{3} \cdot$ Fiorenzo Laghi $^{1}$
}

Received: 8 April 2021 / Accepted: 20 May 2021 / Published online: 29 May 2021

(c) The Author(s) 2021

\begin{abstract}
Purpose The COVID-19 lockdown measures have had a significant impact on risk behaviors as alcohol use and disordered eating. However, little is known about a serious health-risk-behavior named "food and alcohol disturbance" (FAD), characterized by engaging in dysfunctional eating on days of planned alcohol consumption. The aim of the present study was to investigate potential factors that may have put young adults at risk or protected against FAD during the COVID-19 lockdown. Methods A sample of 447 young adults (280 females, 167 males; range 18-26) completed an online survey during the country's nationwide lockdown composed of self-reported measures assessing FAD behaviors, alcohol consumption, compensatory behaviors, eating and weight concerns, social support, emotion regulation strategies, and living arrangement.

Results Our findings showed that FAD was significantly and positively correlated to alcohol consumption, use of laxatives, self-induced vomiting, eating and weight concerns, and expressive suppression, and negatively correlated to social support and living with family. Hierarchical regression analysis revealed that alcohol consumption, eating concern, and expression suppression positively predicted FAD, while social support and living with family were negative predictors.

Conclusions Our results suggest that during the COVID-19 lockdown, preoccupation with eating and the use of expressive suppression may have increased vulnerability to FAD; conversely, perceived social support and living with family may have been a source of protection against this dysfunctional behavior.

Level of evidence Level V, descriptive study.
\end{abstract}

Keywords Drunkorexia $\cdot$ Food and alcohol disturbance $\cdot$ COVID-19 $\cdot$ Emotion regulation $\cdot$ Social support $\cdot$ Living arrangement

\section{Introduction}

The coronavirus disease (COVID-19) that first appeared in China, has rapidly spread worldwide becoming a global pandemic [1]. To mitigate and manage the health emergency, containment measures have been introduced by governments

Fiorenzo Laghi

fiorenzo.laghi@uniroma1.it

1 Department of Social and Developmental Psychology, Sapienza University of Rome, via dei Marsi, 7800185 Rome, Italy

2 Department of Human Sciences, European University of Rome, Rome, Italy

3 Department of Dynamic and Clinical Psychology, and Health Studies, Sapienza University of Rome, Rome, Italy of countries affected by COVID-19. Italy was the first European country to be deeply hit by the pandemic and to adopt a nationwide lockdown that was ordered on March 9th, 2020 in an attempt to control the viral transmission [2]. Lockdown measures involved that people stay home except for emergencies, shopping for basic necessities, health problems, and to go to work (in the case smart-working practices were not possible). Schools were temporary closed, as well as nonessentials shops, and any form of gathering of people in public places or locations accessible to the public was prohibited. Although these restrictions were necessary to contain the transmission of the virus and the pressure on the healthcare system, available evidence has highlighted the significant impact that lockdown measures have had on people's psychological well-being and health-related behaviors [3-6]. Indeed, it was found that the prolonged and mandatory home confinement has had an effect on the engagement 
of dysfunctional behaviors, such as alcohol use [7, 8] and disordered eating [9-11]. Specifically, it has been noted that during the COVID-19 lockdown, individuals have used alcohol and food in an attempt to respond to the negative affect and stress experienced $[8,10]$. Indeed, long isolation and social distancing may increase negative emotions and stress, and disordered eating and alcohol consumption may serve as a way of coping with distress related with an uncertain situation as the pandemic $[8,12]$.

However, to our knowledge, no study so far has investigated an emerging and serious combination of disordered eating and alcohol consumption named "food and alcohol disturbance" (FAD) [13] during the lockdown, and the potential factors that may have been involved in protecting or increasing vulnerability to this behavior. Sometimes referred to also as "drunkorexia" $[14,15]$, FAD concerns a variety of unhealthy eating behaviors in which people engage in preparation or in response to alcohol consumption [16], and can include calorie restriction, fasting, self-induced vomiting, use of laxatives and/or diuretics, and excessive exercising [17-20]. Indeed, FAD is typical of individuals who choose to engage in diet-related behaviors before or after drinking large amounts of alcohol, to compensate for calories consumed through alcoholic beverages for the fear of gaining weight, or to enhance the intoxicating effects of alcohol $[18,21,22]$. Recently, researchers have proven that FAD is predicted by poor body esteem, high sensation seeking [23, 24], and drive for thinness [25], thus suggesting that people may use this at-risk behavior to pursue an idealized body image. Moreover, in recent studies [26], FAD appeared to be driven by motivations analogous to eating and substance use disorders: applying the Cooper's alcohol motivation model, researchers found that enhancement and conformity motives were both related with compensatory behaviors, suggesting that young adults may limit their caloric intake on drinking days to comply with social expectations and to be accepted by others [26].

FAD behaviors are a quite frequent among young people. Before COVID-19 outbreak, from the international prevalence of young adults reported limiting their caloric intake on days they had planned to drink alcohol ranged from 37 to $46 \%$ [22, 27, 28]. In Italy, the pre-pandemic occurrence of FAD behaviors was of about $32 \%$ in young adults [29] and $13 \%$ in adolescents [30].

Gender differences in FAD behaviors are generally inconsistent, as emerged by previous research. Most studies suggest the absence of gender differences in FAD frequency $[16,31,32]$. However, some authors found that women (vs. men) are significantly more likely to engage in restricting behaviors before drinking alcohol $[33,34]$, and are also more likely to engage in FAD behaviors to enhance alcohol's effects [20]. Further evidence suggested that men are more likely to work out to manage their caloric intake in preparation or in response to alcohol consumption, whereas women usually prefer alternative strategies, such as skipping meals and purging [35]. The repeated combination of alcohol consumption and food restriction represents an important health issue because of its association with several detrimental consequences, such as memory lapses, psychological distress, and tendency to engage in at-risk behaviors [27, 36, 37].

Existing literature has repeatedly underlined that alcohol and food are substances that individuals may use in an attempt to deal with and manage negative and stressful emotional experiences they are unable to regulate with more adaptive strategies [20,38]. Indeed, it has been noted [39-41] that both disordered eating and alcohol use are related to difficulties regulating emotions and managing situations involving negative affect. Specifically, it has been showed that the lockdown measures may exacerbate such difficulties in emotion regulation, which may increase the vulnerability for eating disorder symptoms [42]. In addition, a significant and recurring use of maladaptive emotion regulation strategies, as expressive suppression, has been found to be a risk factor for both alcohol use and dysfunctional eating [39, 43, 44]. Eating and weight concerns are also factors associated with a greater risk for dysfunctional eating behaviors [45]. Indeed, preoccupation with food, calories, and the fear of gaining weight may predispose people to dieting and purging behaviors to gain a sense of control on external events or internal feelings [46, 47]. An increase in preoccupation with eating and weight has been showed during the pandemic and dysfunctional eating behaviors may function as a means of regain control in the current crisis characterized by uncertainty and inconstancy [48].

Moreover, previous studies have indicated that even living arrangement seems to influence dysfunctional eating and drinking behaviors [18, 49, 50]. Specifically, living alone during the COVID-19 pandemic in a context of loneliness and isolation may increase vulnerability for healthrisk behaviors [12, 51], affecting the occurrence of both unhealthy eating behaviors and alcohol use [49, 50, 52]. Conversely, living with family has appeared to be a protective factor that may help control the engagement in these risk behaviors [18, 53]. In the same way, the perception of being understood and supported in stressful situations has also been found to be a protective factor against dysfunctional eating and alcohol consumption [54, 55]. For instance, it has been highlighted [54] that tangible social support, as expecting help in case of getting sick or emergency, and the possibility of being able to rely on someone to talk to or relax with, may protect against alcohol involvement. Social support has also been found to play a role in mitigating the impact of different stressors in the context of epidemic diseases [56]. 
The aim of the present study was to investigate potential risk and protective factors that during the COVID-19 lockdown may have been involved in the engagement of FAD among young adults. Specifically, the current research was aimed at investigating the association of FAD with alcohol consumption, compensatory behaviors, emotional regulation strategies, eating and weight concerns, social support perceived, and living arrangement during the lockdown period; furthermore, the research was aimed at exploring the role of preoccupations with eating and weight, social support, living alone and living with family, and emotion regulation strategies in predicting FAD. To our knowledge, this was the first study to be focused on FAD and to explore factors that may have increased the vulnerability or, conversely, have protected young people against this health-risk behavior during the lockdown. In line with prior research [47, 48], we hypothesized that eating and weight concerns may be thoughts that could drive young adults to engage in FAD behaviors in an attempt to gain control over their internal states and external circumstances. Furthermore, consistent with previous studies $[50,52]$, we hypothesized that living alone during the pandemic lockdown, in a condition of prolonged social isolation, may be a risk factor for engaging in FAD, as well as the use of dysfunctional strategies to regulate emotions, as existing literature suggests [8]. Conversely, living with family and perceiving social support may function as protective factors against FAD, in line with available evidences [53-55].

\section{Methods}

\section{Participants and procedure}

The sample consisted of 447 young adults (280 females and 167 males) with a mean age of 23.00 years $(\mathrm{SD}=1.93$; range 18-26). They were required to live in Italy during the COVID-19 lockdown to participate in the study. In terms of their job status, $62 \%$ were students, $20 \%$ were employees, $7 \%$ were unemployed, $6 \%$ were trainees, and $5 \%$ were selfemployed. Regarding participants' job condition during the lockdown, $46 \%$ reported that their work was fully or partially suspended due to the lockdown measures, $32 \%$ reported that they did not have a job, and finally, $22 \%$ continued to work without any suspension. A snowball sampling method was used for the recruitment of the participants for the survey. Data were collected in April and May, 2020 during the country's nationwide lockdown, using an anonymous online survey, which was shared through the University website. Prior to participation in the study, individuals were invited to read the informed consent form and explicitly give their agreement to take part to the research. Of the individuals who agreed to participate in the study, $96 \%$ fully completed all the required measures. The anonymity and confidentiality of the results, as well as the voluntary nature of the research participation were guaranteed. The participants were informed that they could leave the study at any time. They did not receive any reward to take part in the study. This survey was reviewed and approved by the Ethics Commission of the Department of Developmental and Social Psychology of Sapienza, University of Rome.

\section{Measures}

\section{FAD}

To assess FAD during the COVID-19 lockdown, participants were asked to answer a single item used in previous studies [22, 30, 57], indicating during the lockdown period, how often they restricted their food, calories, or carbohydrates on days they planned to drink alcohol to avoid weight gain. Response options ranged from 1 (never) to 5 (often). According to Laghi, Bianchi et al. [57] and Pompili and Laghi [30], this measure provided a valid indicator of FAD behaviors.

Following the procedure suggested in prior research [30], young adults who engaged in restrictive eating or drinking days were categorized as "restrictors", whereas those who reported never engaging in FAD behaviors were categorized as "non-restrictors". We considered as indicating no FAD tendencies, only non-reported restrictive eating in response to alcohol use (answer option $1=$ never).

\section{Alcohol consumption}

Alcohol Use Disorders Identification Test-Consumption (AUDIT-C) is brief alcohol screen used to identify a risky or harmful alcohol consumption. It is the brief version of the Alcohol Use Disorders Identification Test (AUDIT) [58], from which it takes only the first three questions, and assesses different dimensions of alcohol consumption: (1) "How often do you have a drink containing alcohol?"; (2) "How many drinks containing alcohol do you have on a typical day when you are drinking?"; (3) "How often do you have six or more drinks on one occasion?". The score for each response ranges from 0 to 4 points. The minimum final score is 0 , and the maximum is 12 . AUDIT translation has been validated by Piccinelli et al. [59], and preliminary analyses of the short version of AUDIT have demonstrated its validity and effectiveness as a screening test for problem drinking in the Italian context [60].

\section{Compensatory behaviors}

The use of inappropriate compensatory behaviors to offset caloric intake during the lockdown period was investigated 
through the administration of three items, which assessed the frequency of the following behaviors: fasting, self-induced vomiting, and use of laxatives. Compensatory behaviors items were scored from 0 to 6 based on the frequency the participant engaged in the three behaviors. Participants were asked to respond using a 4-point Likert scale $(0=$ never; $2=$ sometimes; $4=$ weekly; $6=$ daily). These three items were selected for the study because of their ease of administration and briefness, along with their effectiveness in assessing the frequency of compensatory behaviors among young people, as suggested in previous studies [20, 57].

\section{Eating and weight concerns}

To assess eating and weight concerns during the lockdown period, two items used in previous studies [20] were administered. The items asked participants to indicate their degree of preoccupation with eating (item 1) and weight (item 2) using a 4 -point Likert scale $(0=$ never; $2=$ sometimes; $4=$ weekly; $6=$ daily). Self-reported weight and height were used to calculate Body Mass Index (BMI).

\section{Living arrangement}

Two items were used to assess the living arrangement, asking participants to indicate both the number and type of persons in the household ("Family", "Roommates", "Partners", "Friends", "Other") during the COVID-19 lockdown. For the purpose of the study, in relation to the number of households, participants who reported to live alone during the lockdown were coded with " 1 ", whereas participants who lived with other people were coded with " 0 ". In respect of the type of households, participants who indicated to live with their family were coded with " 1 ", while participants who lived with other types of persons were coded with " 0 ".

\section{Social support}

Two designed ad hoc items were used to evaluate the social support perceived during the lockdown: "Think about people you keep in contact with on a daily basis. Do you feel that they can understand and / or support you in case of need?". This question was referred to both in-person contacts (item 1) and distance contacts (item 2). Participants responded to items on a 3-point Likert scale: 0 (No or I do not have any contact), 1 (Only someone), 2 (Yes, most of them). The two items were summed to yield a total score of perceived social support.

\section{Emotion Regulation Questionnaire}

The Emotion Regulation Questionnaire (ERQ) [61] is a 10-item instrument designed to assess two Emotion
Regulation strategies: Cognitive Reappraisal (6 items) and Expressive Suppression (4 items). Each item is rated on a 7-point Likert-type scale ranging from 1 (strongly disagree) to 7 (strongly agree). The Italian version of ERQ has demonstrated to have good psychometric properties [62]. In the present study, internal consistency coefficients were satisfactory for both Cognitive Reappraisal $(\alpha=0.80)$ and Expressive Suppression $(\alpha=0.75)$.

\section{Statistical analysis}

All data analyses were conducted using SPSS Statistics Version 25.0. Preliminary, consistent with prior research $[36,63]$, gender differences were investigated by conducting a series of one-way analyses of variance (ANOVAs) on the study variables: FAD, alcohol consumption, compensatory behaviors (fasting, vomiting and use of laxatives), living arrangement (living alone and living with family), social support, eating and weight concerns, and BMI selfreported. We carried out a multivariate analysis of variance (MANOVA) on Emotion Regulation dimensions. For this multivariate analysis, Wilks' $\lambda$ criterion was used. Next, Chi-square tests were performed to investigate gender and age differences between restrictors and non-restrictors; for comparative purposes, the sample was divided into two age groups (18-22 years vs. 23-26 years). To examine differences between the two groups on study variables, a series of ANOVAs and a MANOVA were carried out. To protect from Type I error, $p$ values for the significance of ANOVAs were adjusted using Bonferroni correction for multiple comparisons ( $p$-adjusted value $=0.005$ ). Partial eta-squared values were calculated as a measure of effect size, and results were interpreted using Cohen's [64] guidelines for determining small (0.01), medium (0.06), and large (0.14) effects.

Furthermore, we performed Pearson's correlations to examine the relationship among the study variables: FAD, alcohol consumption, compensatory behaviors, living arrangement, social support, eating and weight concerns, Emotional Regulation dimensions, gender, age, and BMI. A hierarchical regression analysis was conducted to assess the contribution of the key variables in predicting FAD. The regression analysis was conducted in five steps with FAD as dependent variable: gender (females $=1$, males $=0$ ), age, BMI, and alcohol consumption were entered as covariates in step 1, to control for their potential confounding effect, as prior research highlighted an association between FAD and these variables [22, 65]. In step 2, living arrangement (living alone and living with family) was entered to test its main effect controlling for gender, age, BMI, and alcohol consumption. The perceived social support was entered in step 3 to test its predictive role in FAD, controlling for the independent effects of the covariates and living arrangement. In step 4, eating and weight concerns were added to 
measure their main effects controlling for the covariates, living arrangement, and social support. Finally, Emotion Regulation dimensions were entered in step 5 to test their predictive power in FAD, controlling for the effects of the covariates, living arrangement, social support, and eating and weight concerns.

\section{Results}

\section{Preliminary analyses}

\section{Gender differences}

One-way ANOVAs showed a significant difference between males and females on Eating concern, $F(1,445)=12.28$, $p=0.001, \eta_{p}{ }^{2}=0.03$ and weight concern, $F(1,445)=17.83$, $p<0.001, \eta_{p}{ }^{2}=0.04$, where females showed a higher mean score than males. A significant difference was also found for BMI, $F(1,445)=9.41, p<0.01, \eta_{p}{ }^{2}=0.02$. Conversely, the two groups did not show any significant difference on FAD, $F(1,445)=2.41, p=0.12, \eta_{p}^{2}=0.01$, alcohol consumption, $F(1,445)=0.65, p=0.42, \eta_{p}^{2}=0.00$, fasting, $F$ $(1,445)=1.45, p=0.23, \eta_{p}{ }^{2}=0.00$, self-induced vomiting,
$F(1,445)=1.01, p=0.31, \eta_{p}{ }^{2}=0.00$, use of laxatives, $F(1,445)=1.77, p=0.18, \eta_{p}{ }^{2}=0.00$, living alone, $F(1$, $445)=2.00, p=0.16, \eta_{p}{ }^{2}=0.00$, living with family, $F(1$, $445)=0.11, p=0.74, \eta_{p}{ }^{2}=0.00$, and social support, $F(1$, $445)=0.87, p=0.35, \eta_{p}{ }^{2}=0.00$.

Finally, MANOVA on Emotion Regulation strategies revealed a significant main effect for gender, $\lambda=0.94, F(2$, $444)=13.65, p<0.001, \eta_{p}{ }^{2}=0.06$. Results of the univariate tests showed that males and females differed on both Cognitive Reappraisal, $F(1,445)=5.39, p<0.05, \eta_{p}{ }^{2}=0.01$, where females reported a higher mean score than males, and Expressive Suppression, $F(1,445)=19.60, p<0.001$, $\eta_{p}^{2}=0.04$, where females showed a lower average score than males (Table 1).

\section{Differences between restrictors and non-restrictors}

The sample consisted of 34 (8\%) young adults who restricted their food, calories, or carbohydrates on days they planned to drink alcohol to avoid weight gain during the lockdown, and 413 (92\%) non-restrictors. The Chi-square tests revealed that restrictors and non-restrictors did not differ in relation to gender, $\chi^{2}(1)=1.86, p=0.17$ and age, $\chi^{2}(2)=1.87, p=0.17$.

Results from ANOVAs showed a significant difference between restrictors and non-restrictors, on alcohol

Table 1 Descriptive statistic (mean, standard deviation, range, frequency, and percentage of study variables) and gender differences

\begin{tabular}{|c|c|c|c|c|c|c|c|c|c|c|c|}
\hline \multirow[t]{2}{*}{ Variable } & & \multicolumn{2}{|c|}{$\begin{array}{l}\text { Total sample } \\
(N=447)\end{array}$} & \multicolumn{3}{|c|}{ Males $(N=167)$} & \multicolumn{3}{|c|}{ Females $(N=280)$} & \multirow[t]{2}{*}{$p$ value } & \multirow[t]{2}{*}{$\eta_{p}^{2}$} \\
\hline & & M & $\mathrm{SD}$ & M & SD & Range & M & SD & Range & & \\
\hline \multicolumn{2}{|l|}{ FAD } & 1.18 & 0.73 & 1.11 & 0.54 & $1-5$ & 1.22 & 0.82 & $1-5$ & ns & - \\
\hline \multicolumn{2}{|l|}{ Alcohol consumption } & 1.92 & 1.75 & 2.01 & 1.90 & $0-10$ & 1.87 & 1.65 & $0-8$ & ns & - \\
\hline \multicolumn{2}{|l|}{ Fasting } & 0.33 & 0.92 & 0.26 & 0.75 & $0-4$ & 0.37 & 1.00 & $0-6$ & $\mathrm{~ns}$ & - \\
\hline \multicolumn{2}{|l|}{ Vomiting } & 0.06 & 0.36 & 0.04 & 0.27 & $0-2$ & 0.07 & 0.41 & $0-4$ & $\mathrm{~ns}$ & - \\
\hline \multicolumn{2}{|l|}{ Use of laxatives } & 0.07 & 0.44 & 0.04 & 0.34 & $0-4$ & 0.09 & 0.48 & $0-4$ & ns & - \\
\hline \multicolumn{2}{|l|}{ Social support } & 3.11 & 0.97 & 3.17 & 0.93 & $0-4$ & 3.08 & 1.00 & $0-4$ & ns & - \\
\hline \multicolumn{2}{|l|}{ Eating concern } & 1.85 & 1.62 & 1.15 & 1.50 & $0-6$ & 2.06 & 1.66 & $0-6$ & $0.001^{\mathrm{a}}$ & 0.03 \\
\hline \multicolumn{2}{|l|}{ Weight concern } & 2.05 & 1.61 & 1.64 & 1.44 & $0-6$ & 2.29 & 1.65 & $0-6$ & $0.000^{\mathrm{a}}$ & 0.04 \\
\hline \multicolumn{2}{|l|}{ Cognitive reappraisal (ERQ) } & 29.38 & 5.72 & 28.57 & 6.08 & $6-42$ & 29.87 & 5.45 & $12-42$ & 0.042 & 0.01 \\
\hline \multicolumn{2}{|l|}{ Expressive suppression (ERQ) } & 13.69 & 4.91 & 14.99 & 4.66 & $4-25$ & 12.91 & 4.90 & $4-28$ & 0.000 & 0.04 \\
\hline \multirow[t]{2}{*}{ BMI self-reported } & & 22.65 & 3.21 & 23.25 & 2.74 & $17.64-37.44$ & 22.29 & 3.41 & $16.56-38.06$ & $0.002^{\mathrm{a}}$ & 0.02 \\
\hline & \multicolumn{2}{|l|}{$N$} & $\%$ & \multicolumn{2}{|c|}{$N$} & $\%$ & $N$ & $\%$ & \multicolumn{2}{|c|}{$p$ value } & $\eta_{p}^{2}$ \\
\hline \multicolumn{12}{|l|}{ Living alone } \\
\hline Yes & \multicolumn{2}{|l|}{15} & 3 & \multicolumn{2}{|c|}{3} & 2 & 12 & \multicolumn{2}{|c|}{4} & & - \\
\hline No & \multicolumn{2}{|l|}{432} & 97 & \multicolumn{2}{|c|}{164} & 98 & 268 & \multicolumn{2}{|c|}{96} & & \\
\hline \multicolumn{12}{|l|}{ Living with family } \\
\hline Yes & \multicolumn{2}{|l|}{374} & 84 & \multicolumn{2}{|c|}{141} & 84 & 233 & 8 & \multicolumn{2}{|c|}{ ns } & - \\
\hline No & \multicolumn{2}{|l|}{73} & 16 & \multicolumn{2}{|c|}{26} & 16 & 47 & 1 & & & \\
\hline
\end{tabular}

$n s$ non-significant

${ }^{\text {a }}$ Differences are significant at the 0.005 level (Bonferroni adjusted $p$ value) 
consumption $F(1,445)=12.12, p=0.001, \eta_{p}{ }^{2}=0.03$, selfinduced vomiting, $F(1,445)=8.96, p<0.01, \eta_{p}{ }^{2}=0.02$, use of laxatives, $F(1,445)=32.65, p<0.001, \eta_{p}{ }^{2}=0.07$, eating concern, $F(1,445)=21.34, p<0.001, \eta_{p}{ }^{2}=0.05$, and weight concern, $F(1,445)=18.78, p<0.001, \eta_{p}{ }^{2}=0.04$, where restrictors obtained higher mean scores than non-restrictors. Conversely, ANOVAs did not show any difference between restrictors and non-restrictors on fasting, $F(1,445)=6.22$, $p<0.05, \eta_{p}{ }^{2}=0.01$, social support, $F(1,445)=4.70$, $p<0.05, \eta_{p}{ }^{2}=0.01$, living alone, $F(1,445)=0.72, p=0.40$, $\eta_{p}{ }^{2}=0.00$, living with family, $F(1,445)=4.63, p<0.05$, $\eta_{p}{ }^{2}=0.01$, and BMI, $F(1,445)=0.92, p=0.34, \eta_{p}{ }^{2}=0.00$. Also MANOVA on Emotion Regulation strategies did not find differences between the two groups, $\lambda=0.99, F(2$, $444)=2.77, p=0.06, \eta_{p}{ }^{2}=0.01$ (Table 2).

\section{Correlations among the variables}

Pearson correlations were performed to examine the relationship among the key variables used in the present study (Table 3 ). FAD was significantly and positively associated with alcohol consumption, vomiting, use of laxatives, eating concern, weight concern, and Expression Suppression, and negatively related to living with family and social support.

\section{Hierarchical regression analysis}

Results revealed that in step 1 gender, age, and BMI did not significantly predict FAD; only alcohol consumption emerged as a significant predictor, $\beta=0.15, p<0.001$. In step 2 , living alone and living with family were added to the model; findings showed that only living with family resulted as a significant and negative predictor of FAD, $\beta=-0.11$, $p<0.05$. Social support entered in step 3 emerged as a negative predictor of FAD as well, $\beta=-0.13, p<0.05$. In step 4 eating and weight concerns were entered, accounting for $5 \%$ of the variance, with eating concern emerging as a significant predictor of FAD, $\beta=0.17, p<0.01$. Finally, introducing Emotion Regulation strategies in step 5, an additional $2 \%$ of the variance was explained; results revealed that only Expressive Suppression emerged as a significant predictor of FAD, $\beta=0.13, p<0.01$; Cognitive Reappraisal was not found to be related to FAD. Overall, the final model accounted for $12 \%$ of the variance (Table 4 ).

\section{Discussion}

The aim of the current study was to explore potential factors that could have been a source of vulnerability or protection for engaging in FAD among a sample of young adults during the COVID-19 lockdown. Our results highlighted that

Table 2 Differences between non-restrictors and restrictors

\begin{tabular}{|c|c|c|c|c|c|c|}
\hline \multirow[t]{2}{*}{ Variable } & \multicolumn{2}{|c|}{ Non-restrictors $(N=413)$} & \multicolumn{2}{|c|}{ Restrictors $(N=34)$} & \multirow[t]{2}{*}{$p$ value } & \multirow[t]{2}{*}{$\eta_{p}^{2}$} \\
\hline & M & SD & M & SD & & \\
\hline Alcohol consumption & 1.84 & 1.69 & 2.91 & 2.15 & $0.001^{\mathrm{a}}$ & 0.03 \\
\hline Fasting & 0.30 & 0.86 & 0.71 & 1.38 & ns & - \\
\hline Vomiting & 0.04 & 0.32 & 0.24 & 0.65 & $0.003^{\mathrm{a}}$ & 0.02 \\
\hline Use of laxatives & 0.04 & 0.31 & 0.47 & 1.11 & $0.000^{\mathrm{a}}$ & 0.07 \\
\hline Social support & 3.14 & 0.95 & 2.76 & 1.23 & ns & - \\
\hline Eating concern & 1.75 & 1.59 & 3.06 & 1.58 & $0.000^{\mathrm{a}}$ & 0.05 \\
\hline Weight concern & 1.96 & 1.59 & 3.18 & 1.49 & $0.000^{\mathrm{a}}$ & 0.04 \\
\hline Cognitive reappraisal (ERQ) & 29.87 & 5.45 & 28.57 & 6.08 & ns & - \\
\hline Expressive suppression (ERQ) & 12.91 & 4.90 & 14.99 & 4.66 & ns & - \\
\hline \multirow[t]{2}{*}{ BMI self-reported } & 22.61 & 3.23 & 23.16 & 2.89 & $\mathrm{~ns}$ & - \\
\hline & $N$ & $\%$ & $N$ & $\%$ & $p$ value & $\eta_{p}^{2}$ \\
\hline \multicolumn{7}{|l|}{ Living alone } \\
\hline Yes & 13 & 3 & 2 & 6 & ns & - \\
\hline No & 400 & 97 & 32 & 94 & & \\
\hline \multicolumn{7}{|l|}{ Living with family } \\
\hline Yes & 350 & 85 & 24 & 71 & ns & - \\
\hline No & 63 & 15 & 10 & 29 & & \\
\hline
\end{tabular}

$n s$ non-significant

${ }^{a}$ Differences are significant at the 0.005 level (Bonferroni adjusted $p$ value) 


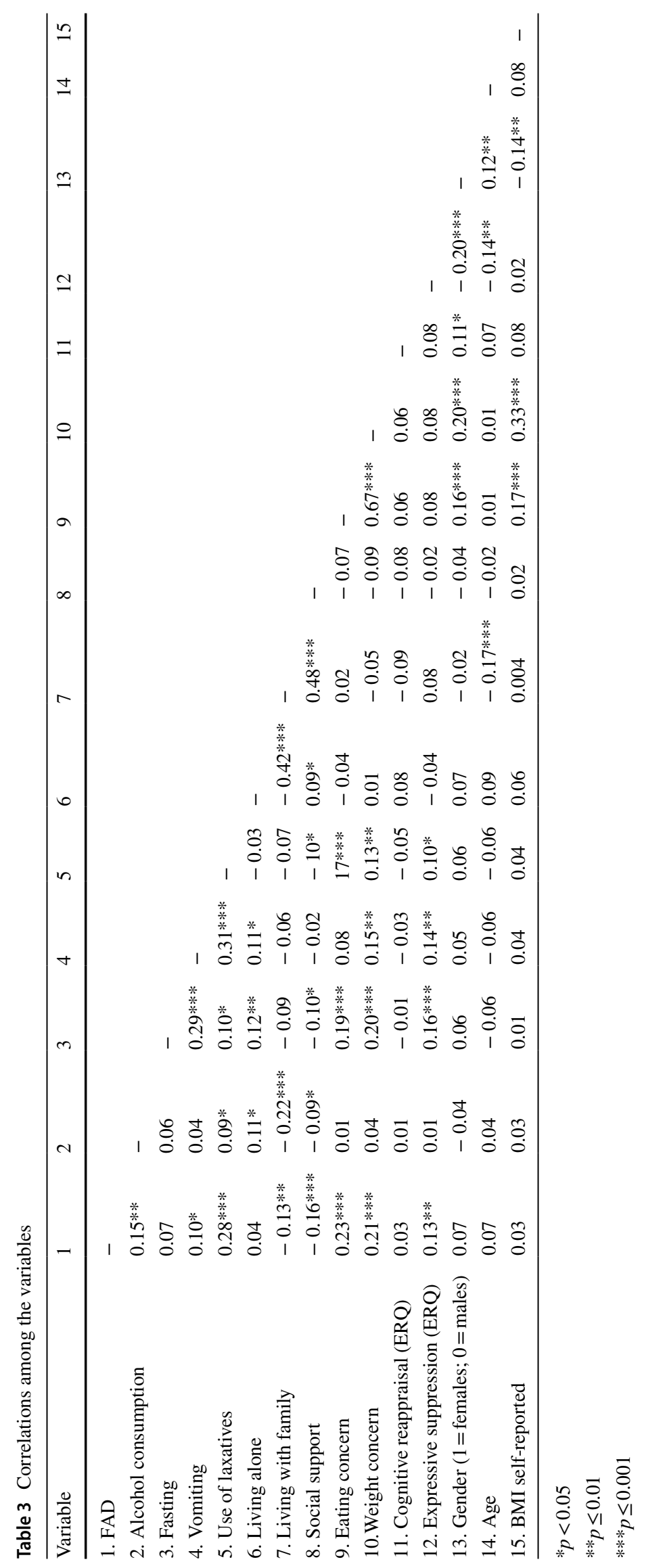


Table 4 Hierarchical regression analysis for variables predicting FAD

\begin{tabular}{|c|c|c|c|c|c|c|c|}
\hline Predictor & $B$ & SE B & $\beta$ & $R^{2}$ & $\Delta R^{2}$ & $d f$ & $\Delta F$ \\
\hline Step 1 & & & & 0.03 & 0.03 & 4.442 & $3.64 * *$ \\
\hline Gender $(1=$ females; $0=$ males $)$ & 0.12 & 0.07 & 0.01 & & & & \\
\hline Age & 0.02 & 0.02 & 0.05 & & & & \\
\hline BMI self-reported & 0.01 & 0.01 & 0.03 & & & & \\
\hline Alcohol consumption & 0.06 & 0.02 & $0.15^{* *}$ & & & & \\
\hline Step 2 & & & & 0.04 & 0.01 & 2.440 & 2.32 \\
\hline Living alone & -0.13 & 0.21 & -0.03 & & & & \\
\hline Living with family & -0.22 & 0.10 & $-0.11^{*}$ & & & & \\
\hline Step 3 & & & & 0.05 & 0.01 & 1.439 & $5.11 *$ \\
\hline Social support & -0.10 & 0.04 & $-0.13 *$ & & & & \\
\hline Step 4 & & & & 0.10 & 0.05 & 2.437 & $11.96 * * *$ \\
\hline Eating concern & 0.07 & 0.03 & $0.17 * *$ & & & & \\
\hline Weight concern & 0.04 & 0.03 & 0.09 & & & & \\
\hline Step 5 & & & & 0.12 & 0.02 & 2.435 & $4.45^{*}$ \\
\hline Cognitive reappraisal (ERQ) & -0.005 & 0.01 & 0.04 & & & & \\
\hline Expressive suppression (ERQ) & 0.02 & 0.01 & $0.13 * *$ & & & & \\
\hline
\end{tabular}

$8 \%$ of young adults engaged in FAD during the lockdown. Compared to the pre-pandemic-estimates, which showed an occurrence of this behavior of about 32\% [29], our data seem to suggest a substantial decrease in the frequency of FAD during the lockdown period. Such difference may be due to the restrictive measures imposed by the COVID-19 lockdown, which did not allow young adults to plan to go out drinking alcohol with their peers. Indeed, FAD represents a socio-cultural practice among young people, and may be influenced by the pressure to conform to peers' group norms by drinking alcohol, and by the desire to achieve a socially acceptance body shape and weight [34]. Thus, it has been suggested that young people may engage in FAD during social activities, where they are more exposed to peer pressure [30].

As expected, both alcohol consumption and compensatory behaviors were related to FAD during the lockdown, although our results highlighted that only self-induced vomiting and laxatives were associated with FAD. Such finding may be related to the evidence that during the lockdown, individuals have reported difficulties in controlling their eating, and it has been suggested that the continuous access to food, feelings of boredom, and loneliness may have been involved in the inability to manage their diet [10]. Thus, among disordered eating behaviors, young adults may have chosen to use laxatives or vomiting, as they have found difficulties limiting caloric intake, for instance, using fasting to avoid an increase in weight. Furthermore, in line with prior research [20, 45, 48], FAD was associated with eating and weight concerns, although only preoccupation with eating emerged as a significant predictor. Our results seem to indicate that during the lockdown, thoughts about food and calories may have been a risk factor for engaging in FAD. This result supports the notion that young people who engage in FAD impose strict rules on themselves on drinking days, which may include the control of the amount as well as the type of food to consume [16]. For instance, there is recent evidence that young adults tend to eat healthier foods the day after drinking, to cleanse or detoxify their bodies [66]. However, as mentioned earlier, the monitoring and control overeating could have been particularly difficult in this period characterized by staying at home with enhanced availability of food [10], giving rise to great concern. Indeed, it has been noted that preoccupation with eating has increased during the pandemic [48], and FAD may have been used as a way to obtain a sense of control both on the self and on external situations as the pandemic, and the uncertainty it involves. In addition, our findings highlighted that during the lockdown, the use of non-adaptive strategies to regulate emotions, such as expressive suppression, may represent a significant predictor of FAD. Thus, the inability to effectively manage and express emotions may increase vulnerability to FAD. Indeed, previous studies underlined that the use of ineffective emotion regulation strategies, which tends to prolong and intensify negative affect, represents a risk factor for both alcohol use and disordered eating $[39,43]$. Specifically, it has been showed that during the lockdown, alcohol and food have been used as a means to comfort and relief form negative emotions [8, 10]. A recent research highlighted that also FAD may be used as a way to cope with aversive affective states young people are not able to manage and express in a more adaptive way; thus, this 
risk behavior may help reducing or distracting from negative affect experienced during the pandemic lockdown [36]. Conversely, having lived with family during the stay-at-home period seems to be a protective factor against FAD. Indeed, in line with available evidence $[18,53]$, the presence of family members may be a source of protection which may help young people to control their engagement in disordered eating behaviors on drinking days. Furthermore, it is plausible to assume that living with family during the lockdown may have provided a source of distraction, helping individuals not to use FAD as a way to distract from and cope with negative emotions. In addition, social support resulted as another protective factor. This finding supports the evidence of the beneficial role of social support during a pandemic [56], and in line with previous studies $[54,55]$, highlighting that the perception of being able to count on a tangible support in case of necessity, and the availability of someone to talk to or relax with, may protect against alcohol consumption and disordered eating.

\section{Limitations}

To our knowledge, this was the first study aimed to investigate potential risk and protective factors that during the COVID-19 lockdown may have been involved in the engagement of FAD among young adults. However, it is important to acknowledge some of the limitations. First, due to the cross-sectional design tested in our study, we were not able to establish the direction of the associations we analyzed; thus, future research could consider the implementation of a longitudinal design to better understand the temporal nature of the variables and to test the potential long-term effects of the risk and protective factors on FAD. Second, our study relied on self-report measures and respondents may have misreported some of the questions of the survey. Third, the study involved a sample of Italian male and female young adults, and thus, our findings might not generalize to non-Italian young adults. Furthermore, we used a single item to assess FAD in line with previous studies [22, 30, 57]. As this item assessed the engagement in FAD for compensating for calories to avoid an increase in weight (which is one of the primary motivations underlying FAD), this measure might have not captured FAD behaviors driven by other motivations, such as enhancing alcohol effects. Thus, this might have affected the number of restrictors in the present study, as well as the use of a snowball sampling, which might have been a potential source of bias. In addition, FAD behaviors might have been impacted by the timing participants completed the survey during the COVD-19 lockdown, for instance, at the very beginning or around the last period. Finally, another limitation of this study was not collecting information about participants' experiences of symptoms of anxiety and depression during the lockdown and the presence of prior eating psychopathology.

\section{What is already known on this subject?}

Existing evidence has highlighted the great impact that the COVID-19 lockdown have had on the engagement in healthrisk behaviors, such as alcohol use and disordered eating. However, to our knowledge, no study has investigated FAD during the lockdown period, and the potential factors that may have protected against or increased vulnerability to this dysfunctional behavior among young adults.

\section{What does this study add?}

The present study revealed that the preoccupation with eating and the use of non-adaptive strategies to regulate emotions, as expressive suppression, may have increased the vulnerability for engaging in FAD during the prolonged stay-at-home period. Conversely, living with family and the perception of social support have resulted to protect against engaging in disordered eating behaviors when alcohol consumption was planned. The findings of our study may have implications both in terms of early identification of young adults at risk for FAD, as well as in terms of prevention, contributing to the implementation of effective programs, which may be focused on helping young adults to develop more adaptive emotion regulation strategies, as being able to tolerate and express negative emotional states, and to strengthen their social support networks.

Funding Open access funding provided by Università degli Studi di Roma La Sapienza within the CRUI-CARE Agreement. This study was not funded.

\section{Declarations}

Conflict of interest The authors declare that they have no competing interests.

Ethical approval All procedures performed in studies involving human participants were in accordance with the ethical standards of the institutional and/or national research committee and with the 1964 Helsinki declaration and its later amendments or comparable ethical standards. Approval from the Research Ethics Board of [blinded for peer review] was obtained before data were collected for the current study.

Informed consent Informed consent was obtained from all individual participants included in the study. 
Open Access This article is licensed under a Creative Commons Attribution 4.0 International License, which permits use, sharing, adaptation, distribution and reproduction in any medium or format, as long as you give appropriate credit to the original author(s) and the source, provide a link to the Creative Commons licence, and indicate if changes were made. The images or other third party material in this article are included in the article's Creative Commons licence, unless indicated otherwise in a credit line to the material. If material is not included in the article's Creative Commons licence and your intended use is not permitted by statutory regulation or exceeds the permitted use, you will need to obtain permission directly from the copyright holder. To view a copy of this licence, visit http://creativecommons.org/licenses/by/4.0/.

\section{References}

1. World Health Organization (2020). WHO Director-General's Opening Remarks at the Media Briefing on COVID-19- 11 march 2020. Retrieved from https://www.who.int/dg/speeches/ detail/who-director-general-s-opening-remarks-at-the-media-brief ing-on-covid-19-11-march-2020

2. Government of Italy (2020). Decree of the President of the Council of Ministers (DPCM) 9 March 2020. Retrieved from https:// www.gazzettaufficiale.it/eli/id/2020/03/09/20A01558/sg

3. Brooks SK, Webster RK, Smith LE, Woodland L, Wessely S, Greenberg N, Rubin GJ (2020) The psychological impact of quarantine and how to reduce it: rapid review of the evidence. Lancet 395(10227):912-920. https://doi.org/10.1016/S0140-6736(20) 30460-8

4. Phillipou A, Meyer D, Neill E, Tan EJ, Toh WL, Van Rheenen TE, Rossell SL (2020) Eating and exercise behaviors in eating disorders and the general population during the COVID-19 pandemic in Australia: initial results from the COLLATE project. Int J Eat Disord. https://doi.org/10.1002/eat.23317

5. Gualano MR, Lo Moro G, Voglino G, Bert F, Siliquini R (2020) Effects of Covid-19 lockdown on mental health and sleep disturbances in Italy. Int J Environ Res Public Health 17(13):4779. https://doi.org/10.3390/ijerph17134779

6. Lippi G, Henry BM, Bovo C, Sanchis-Gomar F (2020) Health risks and potential remedies during prolonged lockdowns for coronavirus disease 2019 (COVID-19). Diagnosis 7(2):85-90. https:// doi.org/10.1515/dx-2020-0041

7. Koopmann A, Georgiadou E, Kiefer F, Hillemacher T (2020) Did the general population in Germany drink more alcohol during the COVID-19 pandemic lockdown? Alcohol Alcohol 55(6):698-699. https://doi.org/10.1093/alcalc/agaa058

8. Neill E, Meyer D, Toh WL, van Rheenen TE, Phillipou A, Tan EJ, Rossell SL (2020) Alcohol use in Australia during the early days of the COVID-19 pandemic: initial results from the COLLATE project. Psychiatry Clin Neurosci 74(10):542-549. https://doi.org/ 10.1111/pcn.13099

9. Ammar A, Brach M, Trabelsi K, Chtourou H, Boukhris O, Masmoudi L, Müller P (2020) Effects of COVID-19 home confinement on eating behaviour and physical activity: results of the ECLB-COVID19 International online survey. Nutrients 12(6): 1583. https://doi.org/10.3390/nu12061583

10. Di Renzo L, Gualtieri P, Cinelli G, Bigioni G, Soldati L, Attinà A, Ferraro S (2020) Psychological aspects and eating habits during COVID-19 home confinement: results of EHLC-COVID-19 Italian online survey. Nutrients 12(7):2152. https://doi.org/10.3390/ nu12072152
11. Sidor A, Rzymski P (2020) Dietary choices and habits during COVID-19 lockdown: experience from Poland. Nutrients 12(6):1657. https://doi.org/10.3390/nu12061657

12. Cooper M, Reilly EE, Siegel JA, Coniglio K, Sadeh-Sharvit S, Pisetsky E, Anderson L (2020) Eating disorders during the COVID-19 pandemic: an overview of risks and recommendations for treatment and early intervention. Eat Disord. https://doi.org/ 10.1080/10640266.2020.1790271

13. Choquette EM, Rancourt D, Kevin Thompson J (2018) From fad to FAD: a theoretical formulation and proposed name change for "drunkorexia" to food and alcohol disturbance (FAD). Int J Eat Disord 51(8):831-834. https://doi.org/10.1002/eat.22926

14. CBS News (2008) Drunkorexia: Health dangers for women. Retrieved from http://www.sbsnews.com/stories/2008/01/23/enter tainment/main3744289.shtml

15. Chambers RA (2008) Drunkorexia. J Dual Diagn 4(4):414-416. https://doi.org/10.1080/15504260802086677

16. Rahal CJ, Bryant JB, Darkes J, Menzel JE, Thompson JK (2012) Development and validation of the compensatory eating and behaviors in response to alcohol consumption scale (CEBRACS). Eat Behav 13(2):83-87. https://doi.org/10.1016/j.eatbeh.2011.11. 001

17. Barry AE, Piazza-Gardner AK (2012) Drunkorexia: understanding the co-occurrence of alcohol consumption and eating/exercise weight management behaviors. J Am Coll Health 60(3):236-243. https://doi.org/10.1080/07448481.2011.587487

18. Bryant JB, Darkes J, Rahal C (2012) College students' compensatory eating and behaviors in response to alcohol consumption. J Am Coll Health 60(5):350-356. https://doi.org/10.1080/07448 481.2011.630702

19. Hunt TK, Forbush KT (2016) Is "drunkorexia" an eating disorder, substance use disorder, or both? Eat Behav 22:40-45. https://doi. org/10.1016/j.eatbeh.2016.03.034

20. Pompili S, Laghi F (2018) Drunkorexia among adolescents: the role of motivations and emotion regulation. Eat behav 29:1-7. https://doi.org/10.1016/j.eatbeh.2018.01.001

21. Buchholz LJ, Crowther JH, Ciesla JA (2018) Examination of the relationships between dietary restraint, alcohol, and adverse problems among women. J Am Coll Health 66(5):384-392. https://doi. org/10.1080/07448481.2018.1431904

22. Eisenberg MH, Fitz CC (2014) "Drunkorexia": exploring the who and why of a disturbing trend in college students' eating and drinking behaviors. J Am Coll Health 62(8):570-577. https://doi. org/10.1080/07448481.2014.947991

23. Hill EM, Lego JE (2019) Examining the role of body esteem and sensation seeking in drunkorexia behaviors. Eat Weight Disord 25(6):1507-1513. https://doi.org/10.1007/s40519-019-00784-8

24. Griffin BL, Vogt KS (2020) Drunkorexia: is it really "just” a university lifestyle choice? Eat Weight Disord. https://doi.org/10. 1007/s40519-020-01051-x

25. Simons RM, Hansen JM, Simons JS, Hovrud L, Hahn AM (2021) Drunkorexia: normative behavior or gateway to alcohol and eating pathology? Addict Behav 112:106577. https://doi.org/10.1016/j. addbeh.2020.106577

26. Ward RM, Galante M (2015) Development and initial validation of the drunkorexia motives and behaviors scales. Eat Behav 18:66-70. https://doi.org/10.1016/j.eatbeh.2015.04.003

27. Giles SM, Champion H, Sutfin EL, McCoy TP, Wagoner K (2009) Calorie restriction on drinking days: an examination of drinking consequences among college students. J Am Coll Health 57(6):603-610. https://doi.org/10.3200/JACH.57.6.603-610

28. Roosen KM, Mills JS (2015) Exploring the motives and mental health correlates of intentional food restriction prior to alcohol use in university students. J Health Psychol 20(6):875-886. https:// doi.org/10.1177/1359105315573436 
29. Lupi M, Martinotti G, Di Giannantonio M (2017) Drunkorexia: an emerging trend in young adults. Eat Weight Disord 22(4):619622. https://doi.org/10.1007/s40519-017-0429-2

30. Pompili S, Laghi F (2018) Drunkorexia: disordered eating behaviors and risky alcohol consumption among adolescents. J Health Psychol. https://doi.org/10.1177/1359105318791229

31. Peralta RL, Barr PB (2017) Gender orientation and alcohol-related weight control behavior among male and female college students. J Am Coll Health 65(4):229-242. https://doi.org/10.1080/07448 481.2016.1271802

32. Pinna F, Milia P, Mereu A, di Santa Sofia SL, Puddu L, Fatteri F, Ghiani A, Lai A, Sanna L, Carpiniello B (2015) Validation of the Italian version of the compensatory eating and behaviors in response to alcohol consumption scale (CEBRACS). Eat Behav 19:120-126. https://doi.org/10.1016/j.eatbeh.2015.08.004

33. Osborne VA, Sher KJ, Winograd RP (2011) Disordered eating patterns and alcohol misuse in college students: evidence for “drunkorexia"? Compr Psychiatry 6(52):e12. https://doi.org/10. 1016/j.comppsych.2011.04.038

34. Peralta RL (2002) Alcohol use and the fear of weight gain in college: reconciling two social norms. Gend Issues 20(4):23-42. https://doi.org/10.1007/s12147-002-0021-5

35. Barry AE, Whiteman S, Piazza-Gardner AK, Jensen AC (2013) Gender differences in the associations among body mass index, weight loss, exercise, and drinking among college students. J Am Coll Health 61(7):407-413. https://doi.org/10.1080/07448481.2013. 823973

36. Laghi F, Pompili S, Bianchi D, Lonigro A, Baiocco R (2020) Exploring the association between psychological distress and drunkorexia behaviors in non-clinical adolescents: the moderating role of emotional dysregulation. Eat Weight Disord. https://doi.org/ 10.1007/s40519-020-00912-9 (Advanced online publication)

37. White AM (2003) What happened? alcohol, memory blackouts, and the brain. Alcohol Res Health 27(2):186

38. Veilleux JC, Skinner KD, Reese ED, Shaver JA (2014) Negative affect intensity influences drinking to cope through facets of emotion dysregulation. Pers Individ Dif 59:96-101. https://doi.org/10.1016/j. paid.2013.11.012

39. Laghi F, Liga F, Pompili S (2018) Adolescents who binge eat and drink: the role of emotion regulation. J Addict Dis 37(1-2):77-86. https://doi.org/10.1080/10550887.2018.1553458

40. Lavender JM, Anderson DA (2010) Contribution of emotion regulation difficulties to disordered eating and body dissatisfaction in college men. Int J Eat Disord 43(4):352-357. https://doi.org/10.1002/ eat. 20705

41. Whiteside U, Chen E, Neighbors C, Hunter D, Lo T, Larimer M (2007) Difficulties regulating emotions: Do binge eaters have fewer strategies to modulate and tolerate negative affect? Eat Behav 8(2):162-169. https://doi.org/10.1016/j.eatbeh.2006.04.001

42. Machado PP, Pinto-Bastos A, Ramos R, Rodrigues TF, Louro E, Gonçalves S, Vaz A (2020) Impact of COVID-19 lockdown measures on a cohort of eating disorders patients. J Eat Disord 8:1-8. https://doi.org/10.1186/s40337-020-00340-1

43. Aldao A, Nolen-Hoeksema S, Schweizer S (2010) Emotion-regulation strategies across psychopathology: a meta-analytic review. Clin Psychol Rev 30(2):217-237. https://doi.org/10.1016/j.cpr.2009.11. 004

44. Aldao A, Jazaieri H, Goldin PR, Gross JJ (2014) Adaptive and maladaptive emotion regulation strategies: interactive effects during CBT for social anxiety disorder. J Anxiety Disord 28(4):382-389. https:// doi.org/10.1016/j.janxdis.2014.03.005

45. Fairburn CG, Harrison PJ (2003) Eating disorders. Lancet 361:407416. https://doi.org/10.1016/S0140-6736(03)12378-1

46. Sassaroli S, Gallucci M, Ruggiero GM (2008) Low perception of control as a cognitive factor of eating disorders. Its independent effects on measures of eating disorders and its interactive effects with perfectionism and self-esteem. J Behav Ther Exp Psychiatry 39(4):467-488. https://doi.org/10.1016/j.jbtep.2007.11.005

47. Sapuppo W, Ruggiero GM, Caselli G, Sassaroli S (2018) The body of cognitive and metacognitive variables in eating disorders: need of control, negative beliefs about worry uncontrollability and danger, perfectionism, self-esteem and worry. Isr J Psychiatry Relat Sci 55(1):55-83

48. Schlegl S, Maier J, Meule A, Voderholzer U (2020) Eating disorders in times of the COVID-19 pandemic - results from an online survey of patients with anorexia nervosa. Int J Eat Disord 53(11):17911800. https://doi.org/10.1002/eat.23374

49. Tani Y, Kondo N, Takagi D, Saito M, Hikichi H, Ojima T, Kondo $\mathrm{K}$ (2015) Combined effects of eating alone and living alone on unhealthy dietary behaviors, obesity and underweight in older Japanese adults: results of the JAGES. Appetite 95:1-8. https://doi.org/ 10.1016/j.appet.2015.06.005

50. Zhang J, Wu L (2015) Cigarette smoking and alcohol consumption among Chinese older adults: do living arrangements matter? Int $\mathrm{J}$ Environ Res Public Health 12(3):2411-2436. https://doi.org/10. 3390/ijerph120302411

51. Vanderbruggen N, Matthys F, Van Laere S, Zeeuws D, Santermans L, Van den Ameele S, Crunelle CL (2020) Self-reported alcohol, tobacco, and Cannabis use during COVID-19 lockdown measures: results from a web-based survey. Eur Addict Res 26(6):309-315. https://doi.org/10.1159/000510822

52. Wicki M, Kuntsche E, Gmel G (2010) Drinking at European universities? a review of students' alcohol use. Addict Behav 35(11):913924. https://doi.org/10.1016/j.addbeh.2010.06.015

53. Fulkerson JA, Larson N, Horning M, Neumark-Sztainer D (2014) A review of associations between family or shared meal frequency and dietary and weight status outcomes across the lifespan. J Nutr Educ Behav 46(1):2-19. https://doi.org/10.1016/j.jneb.2013.07.012

54. Peirce RS, Frone MR, Russell M, Cooper ML (1996) Financial stress, social support, and alcohol involvement: a longitudinal test of the buffering hypothesis in a general population survey. Health Psychol 15(1):38-47. https://doi.org/10.1037/0278-6133.15.1.38

55. Stice E, Presnell K, Spangler D (2002) Risk factors for binge eating onset in adolescent girls: a 2-year prospective investigation. Health psychol 21(2):131-138

56. Main A, Zhou Q, Ma Y, Luecken LJ, Liu X (2011) Relations of SARS-related stressors and coping to Chinese college students' psychological adjustment during the 2003 Beijing SARS epidemic. J Couns Psychol 58(3):410-423. https://doi.org/10.1037/a0023632

57. Laghi F, Bianchi D, Sinibaldi N, Porrone M, Pompili S, Lonigro A, Baiocco R (2020) Funzionamento familiare e comportamenti di drunkorexia in adolescenza. Psicologia clinica dello sviluppo 24(1):59-82

58. Babor TF, de la Fuente JR, Saunders J, Grant M (1992) AUDIT: the alcohol use disorders identification test: guidelines for use in primary health care. World Health Organization, Geneva

59. Piccinelli M, Tessari E, Bortolomasi M, Piasere O, Semenzin M, Garzotto N, Tansella M (1997) Efficacy of the alcohol use disorders identification test as a screening tool for hazardous alcohol intake and related disorders in primary care: a validity study. BMJ 314(7078):420. https://doi.org/10.1136/bmj.314.7078.420

60. Struzzo P, De Faccio S, Moscatelli E et al (2006) Gruppo di ricerca PRISMA. Identificazione precoce dei bevitori a rischio in assistenza primaria in Italia: Adattamento del questionario AUDIT e verifica dell'efficacia d'uso dello short-AUDIT test nel contesto nazionale. Boll Farmacod Alcoolismo 29(12):20-25

61. Gross JJ, John OP (2003) Individual differences in two emotion regulation processes: implications for affect, relationships, and wellbeing. J Pers Soc Psychol 85(2):348-362. https://doi.org/10.1037/ 0022-3514.85.2.348 
62. Balzarotti S, John OP, Gross JJ (2010) An Italian adaptation of the emotion regulation questionnaire. Eur J Psychol Assess 26:61-67. https://doi.org/10.1027/1015-5759/a000009

63. Pietrabissa G, Rossi A, Gaudenzi M, Bertuzzi V, Tagliagambe A, Volpi C, Simpson S (2018) Drunkorexia: empirical investigation and analysis of the characteristics of the phenomenon in an Italian sample of adolescents and young adults. Psychol Soc Educ 10(3):285-299. https://doi.org/10.25115/psye.v10i3.2135

64. Cohen J (1988) Statistical power analysis for the behavioral sciences. Lawrence Erlbaum Associates, Hillsdale

65. Wilkerson AH, Hackman CL, Rush SE, Usdan SL, Smith CS (2017) "Drunkorexia": understanding eating and physical activity behaviors of weight conscious drinkers in a sample of college students. J Am
Coll Health 65(7):492-501. https://doi.org/10.1080/07448481.2017. 1344848

66. Scott S, Muir C, Stead M, Fitzgerald N, Kaner E, Bradley J, Adamson A (2020) Exploring the links between unhealthy eating behaviour and heavy alcohol use in the social, emotional and cultural lives of young adults (aged 18-25): a qualitative research study. Appetite 144:104449. https://doi.org/10.1016/j.appet.2019.104449

Publisher's Note Springer Nature remains neutral with regard to jurisdictional claims in published maps and institutional affiliations. 